\title{
Synthesis and Characterization of Copper Nanoparticles by Bis-(Acetylacetonato)-Copper (II) Using Nonionic Surfactants and the Effect of Their Structures on Nanoparticles Size and Yield
}

\author{
Hamidreza Kamrani \\ Department of Chemistry, Nanotechnology Laboratory, University of Isfahan, Isfahan, Iran \\ Email: Hr.kamrani@gmail.com
}

How to cite this paper: Kamrani, H. (2018) Synthesis and Characterization of Copper Nanoparticles by Bis-(Acetylacetonato)-Copper (II) Using Nonionic Surfactants and the Effect of Their Structures on Nanoparticles Size and Yield. Open Journal of Inorganic Non-metallic Materials, 8, 11-21.

https://doi.org/10.4236/ojinm.2018.82002

Received: April 20, 2018

Accepted: April 26, 2018

Published: April 29, 2018

Copyright ( 2018 by author and Scientific Research Publishing Inc. This work is licensed under the Creative Commons Attribution International License (CC BY 4.0).

http://creativecommons.org/licenses/by/4.0/

\begin{abstract}
Between all precursors of copper complex, bis-(acetylacetonato)-copper (II) and bis-oxalate copper (II) with very close structures are two of the best representatives for copper nanoparticles synthesis. In this research, only bis-(acetylacetonato)-copper (II) in presence of some effective non-ionic surfactants such as Triton X-100, Dodecylamine, Tween 80 and also triphenylphosphine as a reducing agent via thermal decomposition process was used for copper nanopaticles synthesis. Two shif-base E19 and E22 complexes were also used for the investigation of these kinds of shif-base complexes capabilities by this method as precursors and all results were compared with each other. Between all surfactants, Triton X-100 gave the best yield with the largest grains. The techniques used for characterization of copper nanoparticles were TEM, EDX, FT-IR and XRD. TG-DTA and CV were used for characterization of bis-(acetylacetonato)-copper (II) complex.
\end{abstract}

\section{Keywords}

Bis-Acetylacetonato-Copper (II), Thermal Decomposition, Nonionic Surfactants, Copper Nanoparticles, Shif-Base Complexes

\section{Introduction}

What caused the appearance of nanotechnology was the impact of high ratio area of materials to their volume that stimulated many researches to open new doors to the science world. In nano scale, some properties especially physical 
properties are breached in comparison of their bulk features. Nanotechnology is divided to three main parts in dried, humid and countable that are usable in some sciences, such as electrical, medical, agriculture and food industry. Totally, there are different methods for synthesis of nanoparticles [1]-[30]. Four main ways are gas phase, humid, mechanical, and in situ. Between all nanoparticles, copper nanoparticles, because of their various precursors and especially because of very different applications, such as electrical, catalytical and optical, are so important [31] [32]. There are different methods for copper nanoparticles fabrication [33]-[41]. But mechanical methods are the methods that are more common for copper nanoparticles fabrication and thermal decomposition is the most economical and easy way [42] [43] [44]. Bis-(acetylacetonato)-copper (II) was selected as a precursor, because its behavior is very same to bis-oxalate copper (II) which has been applied before and is decomposed at enough low temperature (about $200^{\circ} \mathrm{C}$ ) to prevent very probable precipitation of the produced metallic particles, and its decomposition gives water and carbon compounds, which does not lead to real human health problems [33] [42]. It was investigated the effect of surfactants structural role in the yield and grain size of nanoparticles too. The role of surfactant here is making of micelle structure that can help for copper nanoparticles dispersion. In other words, they can be considered in dual roles, as a capping agent and also extractants. Different surfactants have the same behavior but with different effects on nanoparticles yield and size [45]. The control of temperature during surfactant and triphenylphosphine addition in dispersion process is very important.

\section{Experimental}

\subsection{Chemicals}

All surfactants consist of Triton X-100, Tween 80, Propane Diol and also Ethylene Glychol, Triphenyl Phosphine, Aqueous Amonia, Acethyl acetonato, Nitrate Tri hydrate and choloroform were purchased from Merck company. Bis-acethyl acetonato copper (II) was synthesized in the laboratory.

\subsection{APPARATUS}

\subsubsection{XRD}

The crystalline phase of colloids was studied by X-ray diffraction (XRD) technique with a bruker D8 advance X-Ray diffractometer (http://www.bruker-axs.com/). Main obvious peaks are in 36.5 and 61.5 degree for $\mathrm{CuO}$ and 43.5, 50.5 and 74 degree for metallic copper nanoparticles. F.c.c lattice copper nanoparticle cell was detected by this technique. The crystallite size $\mathrm{D}$ of the sample was estimated using the Scherer's equation, $(0.9 \lambda) /(\cos \beta)$, by measuring the line broadening of main intensity peak, where $\lambda$ is the wavelength of $\mathrm{Cu} \mathrm{K} \alpha$ radiation, $\beta$ is the full width at half-maximum, and $\theta$ is the Brag's angle. An estimation of particle size by usage of Scherrer's equation revealed the crystallite size of about 21,18 and 12 $\mathrm{nm}$ using Triton $\mathrm{X}-100$ (t-octyl-(OCH2CH2) $\mathrm{xOH}, \mathrm{x}=9,10)$, Tween-80, and 
dodecyl amine as surfactants respectively that is shin own in Figure 1.

\subsubsection{TEM}

The microstructure, particle size and morphologies were investigated by a Leo 912 AB transmission electron microscopy (TEM). Micrograph shows the uniform dispersion of synthesized nanoparticles. The result of copper nanoparticles production by Triton X100 and bis-(acetylacetonato)-copper (II) with TEM micrograph shows about $20 \mathrm{~nm}$ grain size (Figure 2).

\subsubsection{FT-IR}

Fourier transform infrared spectroscopy (FT-IR), JASCO.JAPAN 6300 (400 $4000 \mathrm{~cm}^{-1}$ ) was used for determination of copper nanoparticles and their purity. Two obvious peaks are $3427 \mathrm{~cm}^{-1}$ for stretching frequency of $\mathrm{O}-\mathrm{H}$ bond of Triton $\mathrm{X}-100$ and $697 \mathrm{~cm}^{-1}$ for $\mathrm{Cu}-\mathrm{O}$ vibration frequency. All both peaks show that there are some non reacted Triton X-100 on the surface of copper nanoparticles and some $\mathrm{CuO}$ as impurity. All impurities are less than 1 percent. Other obvious remaining peaks are related to metallic copper nanoparticles (Figure 3).

\subsubsection{EDX}

EDX spectrum by Seron-AIS 2300 Korea was run just for qualitative analysis and copper nanoarticles production confirmation. In EDAX spectrum with three surfactants Triton X-100, Tween 80 and dodecyl amine just metallic copper in all spectrums was specified. The spectrum of bis-acetyl acetonato copper (II) and Triton X-100 as an example is shown in Figure 4. This spectrum can be used just for qualitative determination.

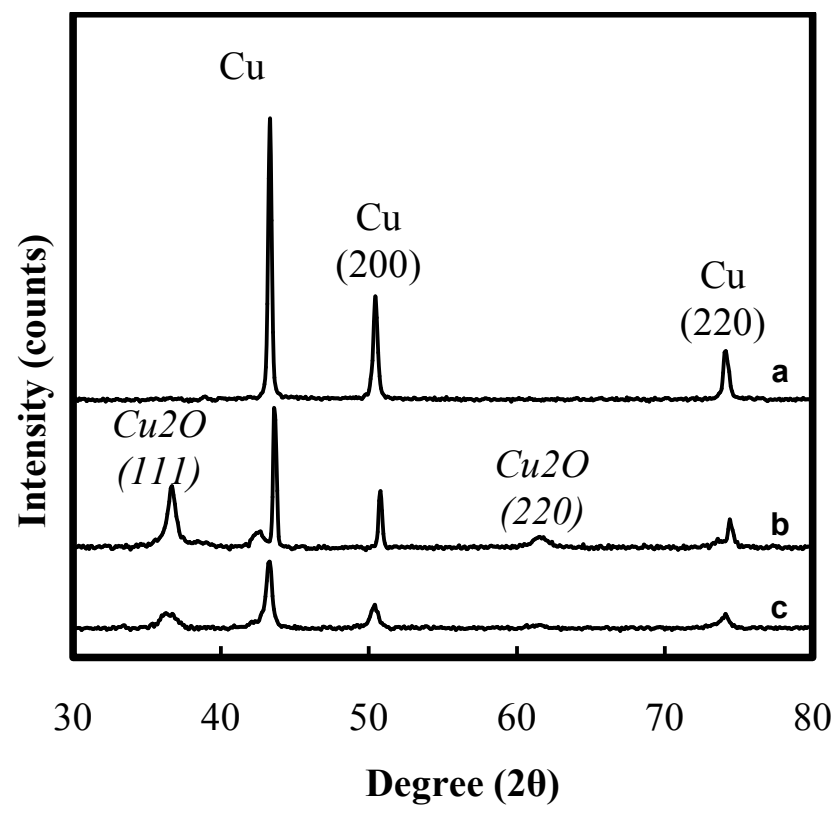

Figure 1. XRD pattern of the copper nanoparticles synthesized using bis-acetylacetonato copper (II) as precursor and (a) Tween 80, (b) Triton X100 and (c) dodecylamine as capping agenta (a) Triton X-100 (b) Tween 80 (c) Dodecyl Amine. 


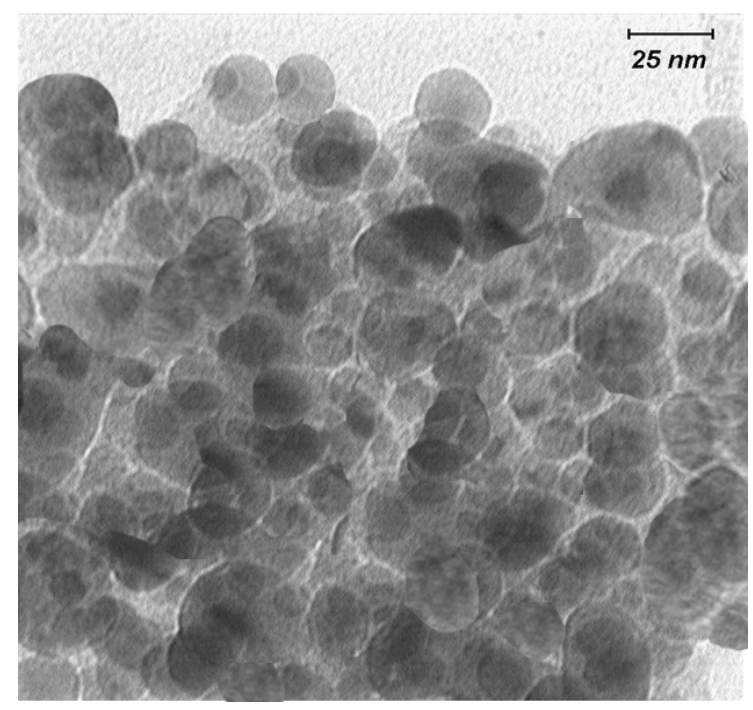

Figure 2. TEM image of the copper nanoparticles synthesized using bis-acetylacetonato-copper (II) as precursor and Triton X-100 as capping agent.

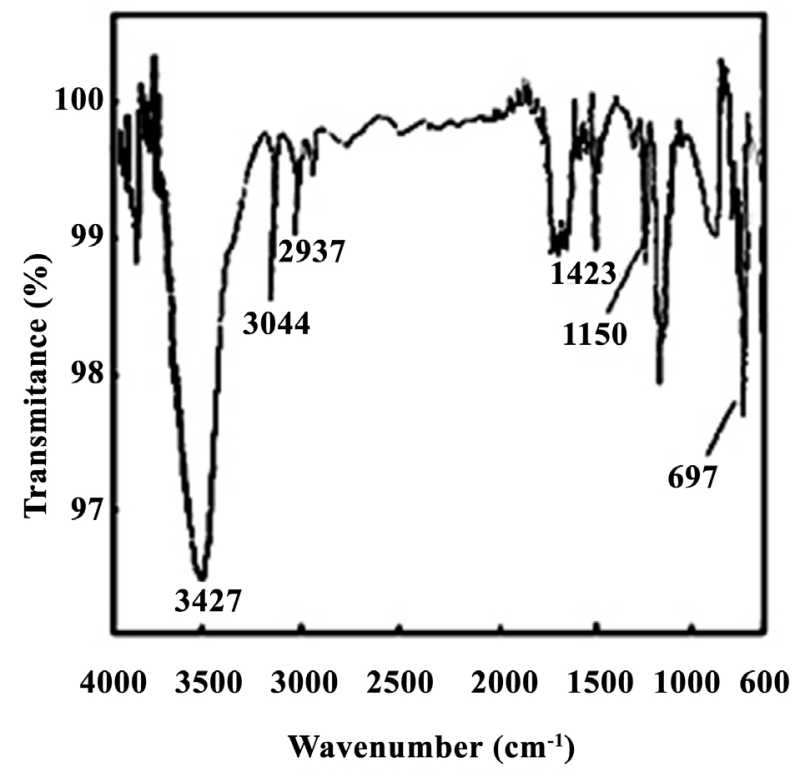

Figure 3. FT-IR spectroscope for copper nanoparticles synthesized by Triton X-100 and bis-acetylacetonato copper (II).

\subsection{The Techniques used for Characterization of Bis-Acetylacetonato-Copper (II)}

\subsubsection{CV}

Cyclic voltammograms (CV) were recorded by using a SAMA Research Analyzer M-500 for copper complex Precursor. The cyclic voltammograms of $\mathrm{Cu}(\mathrm{acac})_{2}$ exhibits an electrochemically irreversible reduction process at $\mathrm{ca}-0.445 \mathrm{~V}$ and 0.072 with unequal ratio of anodic to cathodic peak currents (ipa/ipc) and peak potential difference of $0.517 \mathrm{~V} \cdot \mathrm{s}$ which is due to the process $\left[\mathrm{Cu}(\mathrm{II})(\mathrm{acac})_{2}\right]$ to $\left[\mathrm{Cu}(\mathrm{I})(\mathrm{acac})_{2}\right]^{-}$that is shown in Figure 5. 


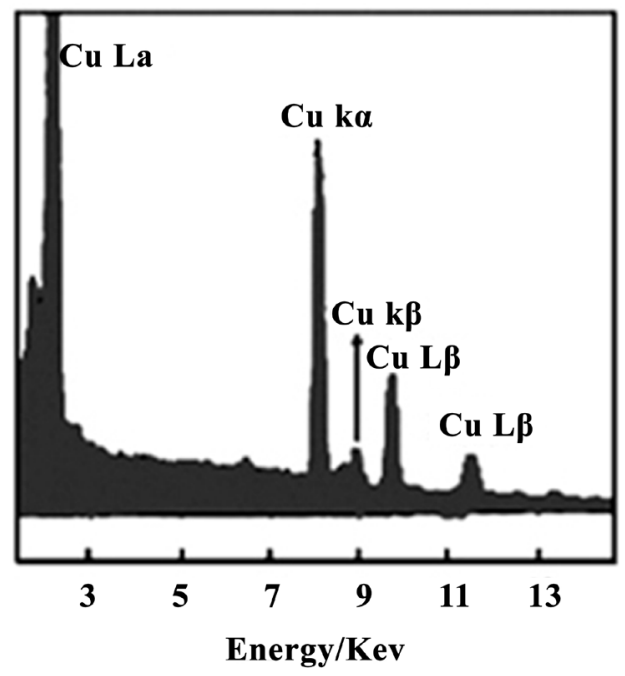

Figure 4. EDAX of copper nanoparticles prepared by Triton X-100 and bis-acacetonato-copper (II).

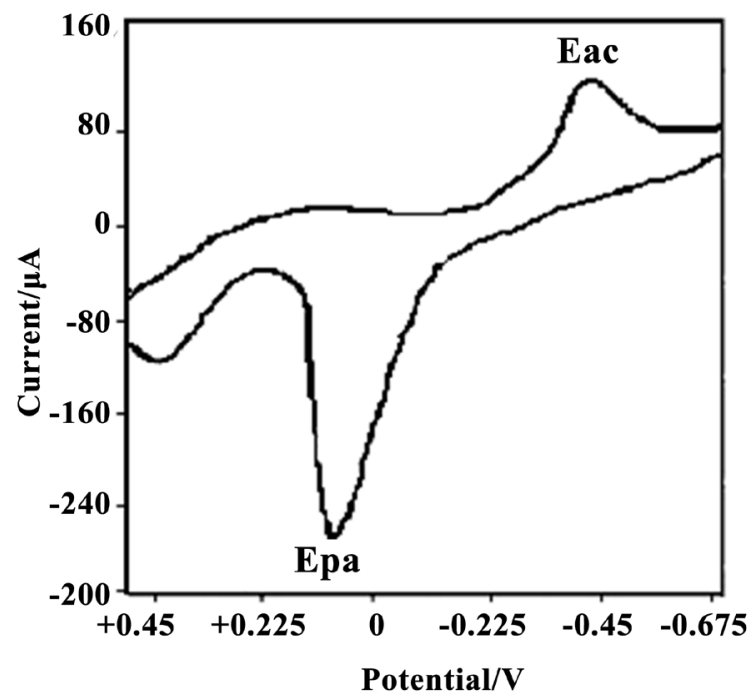

Figure 5. Cyclic voltammogram of bis-(acetylacetonato)-copper (II) as precursor, $\mathrm{c}=3 \times 10^{-3} \mathrm{~mol} \cdot \mathrm{L}^{-1}$, in DMF $(25 \mathrm{~mL})$ containing $0.1 \mathrm{~mol} \cdot \mathrm{L}^{-1} \mathrm{TBAP}$ as supporting electrolyte at $298 \mathrm{~K}$. Scan rate, $0.1 \mathrm{~V} \cdot \mathrm{s}^{-1}$.

\subsection{2. (TG-DTA)}

Thermal gravimetric differential thermal analysis (TG-DTA) measurement was carried using a Mettler TA4000 system (http://ir.mt.com). By this technique the points of thermal decomposition of bis-(acetylacetonato)-copper (II) can be determined. Thermal lost weight was $67 \%$. Corresponding to the TG result, one weight loss step in the DTA curve at $320^{\circ} \mathrm{C}$ is assigned to the decomposition of acetylacetonate (Figure 6).

\subsection{Synthesis of Bis-(Acetylacetonato)-Copper (II)}

$10 \mathrm{gr}$ of Copper Nitrate Tri hydrate was dissolved in $100 \mathrm{ml}$ distillated water. To 


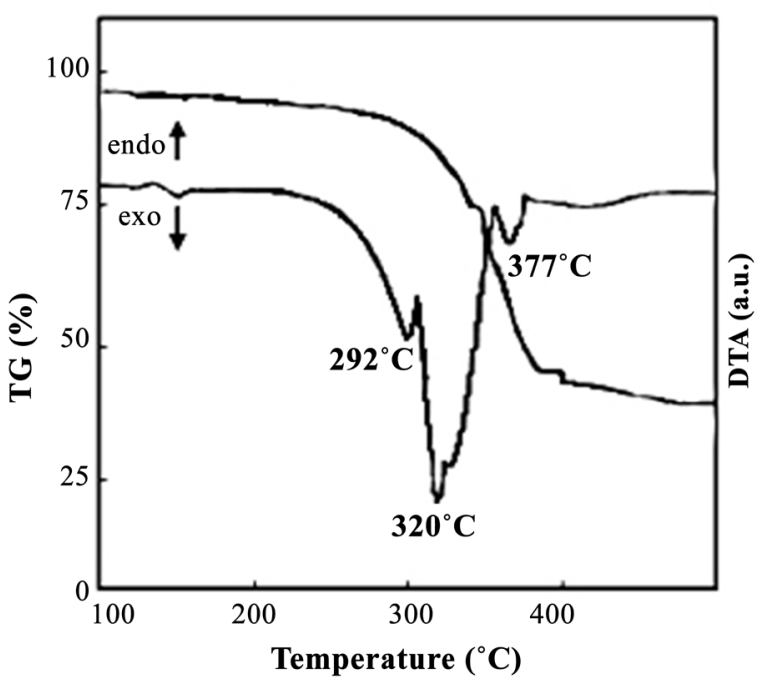

Figure 6. TG-DTA curve for bis-(acetylacetoneto)-copper (II) as precursor.

result $\mathrm{Cu}\left(\mathrm{NH}_{4}\right)^{2+}, 15 \mathrm{ml}$ aqueous ammonia was added to form blue precipitate. Then $11 \mathrm{ml}$ acetyl acetonate was mixed with blue precipitate in drop wise stirring manner. The product is non pure $\mathrm{Cu}(\mathrm{acac}) 2$ that is washed with choloroform to be purred.

\subsection{Synthesis of Copper Nanoparticles by Bis-Acetylacetonate Copper (II) and Different Surfactants}

Bis-(acetylacetonato)-copper (II) was added to dodecyl amine as surfactant to create a homogenous solution, then refluxed for $1 \mathrm{~h}$ at $140^{\circ} \mathrm{C}$. Then triphenyl phosphine (a reducing agent) was heated and stirred. The supernatant was removed, and the nanoparticle sediment was washed, dried (73\% yield). The same procedure was used by Tween-80 (72\% yield) and Triton X-100 (99\% yield) as non-ionic surfactants. Also this was done with propandiol (92\% yield) and ethylene glycol (89\% yield) as two alcohols.

\section{Result and Discussion}

From four used surfactants propandiol, Ethylene Glychol, Triton X-100 and Tween 80, the best yield is for Triton X-100. In Triton X-100 structure there is an active polar part and a long non polar tail that helps it to react with acetyl acetonato copper (II) strongly. Tween 80 also has same behavior that produces a good micelle with the $\mathrm{Cu}(\mathrm{acac})_{2}$ too. Another good surfactant is Dodecyle amin that can produces a micelle structure and helps dispersion of colloidal structure of acetonato copper (II). For Propane diol and Ethylene glychol also this issue can be repeatable. The yields of these two alcholols are considerable. So they can be the best alcohols for the thermal decomposition method (Table 1).

But two E19 and E22 shif-base complexes did not give good results with non of mentioned surfactants (Figure 7 \& Figure 8).

As it was implied before, the behavior of Bis-oxalato copper (II) and Bis-acetyle 
Table 1. The effect of nonionic surfactants on size and yields on copper nanoparticle using bis-(acetylacetonato)-copper (II) as precursor.

\begin{tabular}{cccc}
\hline $\begin{array}{c}\text { Grain Size } \\
\text { in } \mathbf{4 3 . 3}^{\circ}(\mathrm{nm})\end{array}$ & Yeild (\%) & Surfactant & Precursor \\
\hline 12.030 & 73.3 & Dodecyl Amine (pure) & Copper acetyl acetonate \\
18.68 & 72 & Tween 80 (pure) & Copper acetyl acetonate \\
21.320 & 99 & Triton X-100 & Copper Acethyl acetonate \\
24.019 & 92.5 & Propan Diol & Copper Acethyl acetonate \\
24.019 & 89 & Etylene glychole & Copper Acethyl acetonate \\
\hline
\end{tabular}

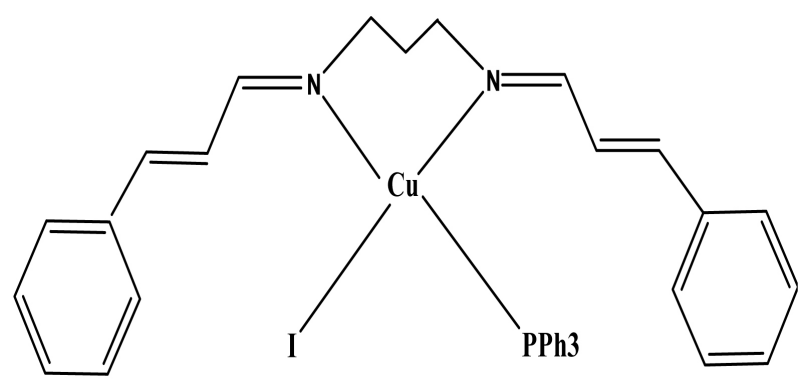

Figure 7. E22 complex.

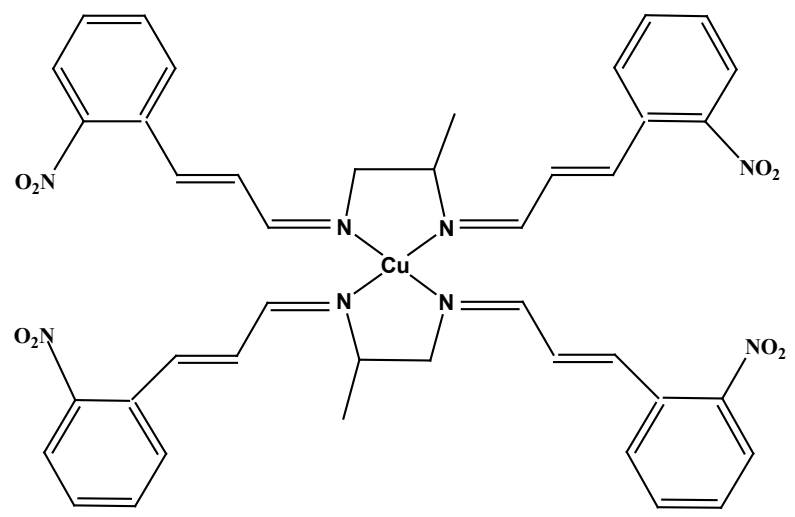

Figure 8. E19 complex.

acetonato copper (II) are very close to each other because of their close structure (Figure 9 \& Figure 10).

Figure 11 shows a plot of the average particle size versus the surfactants. This finding is significant, demonstrating the important role of surfactant in control of particle size. These observations may hint at this implication that the mechanistic origin of the particles size depends on capping agent structure and activity of surfactants. These results are achieved by XRD pattern and Scherrer's equation.

\section{Conclusion}

In copper nanoparticle production, triphenylphosphine is the only agent for 
<smiles>O=C1O[C]2OC3C(=O)O[Ge]23OC1=O</smiles>

Figure 9. Bis-acetyleacetonato-copper (II).<smiles></smiles>

Figure 10. Bis-oxalato-copper (II).

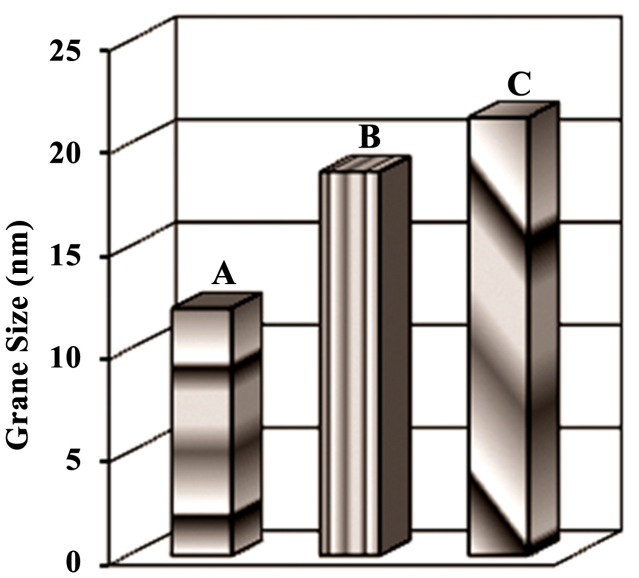

Figure 11. The plot of copper nanoparticle grain sizes synthesized using bis-acetylacetonato-copper (II) as precursor, $\mathrm{A}=$ Dodecyl Amine, $\mathrm{B}=$ Tween 80 and $\mathrm{C}=$ Triton $\mathrm{X}-100$ as capping agents.

reduction of copper (II) cation to metallic copper nano particles. Two main factors in morphology, yield and grain size of produced copper nanoparticles are accurate suitable non ionic surfactants and copper precursors selection via thermal decomposition method. The basis of mechanism in this process is micelle structure formation and nonionic surfactants have a good ability for this purpose. The smallest copper nanoparticles are synthesized by Dodecylamine and the largest by Triton-X100.

\section{Acknowledgements}

The author thanks Dr. Ataollah Nosrati (Edith Cowan University of Australia) for his useful remarks and advices.

\section{Conflicts of Interest}

The authors declare no conflicts of interest regarding the publication of this paper. 


\section{References}

[1] Jones, A.C. and Hitchman, M.L., Eds. (2009) Overview of Chemical Vapor Deposition, Chemical Vapor Deposition: Precursors, Processes and Applications. Royal Society of Chemistry. http://www.rsc.org/

[2] Ashraf, U. and Khan, B. (2013) Synthesis and Characterization of NiO Nanopowder by Sol-Gel Method. International Journal of Science and Research, 4, 2405-2408.

[3] Chandra, S., Kumar, A. and Tomar, P.K. (2014) Synthesis and Characterization of Copper Nanoparticles by Reducing Agent. Journal of Saudi Chemical Society, 18, 149-153. https://doi.org/10.1016/j.jscs.2011.06.009

[4] Chatterjee, A.K., Sarkar, R.K., Chattopadhyay, A.P., Aich, P., Chakraborty, R. and Basu, T. (2012) A Simple Robust Method for Synthesis of Metallic Copper Nanoparticles of High Antibacterial Potency against E. coli. Nanotechnology, 23, Article ID: 085103. https://doi.org/10.1088/0957-4484/23/8/085103

[5] Cheng, W., Zhang, W., Hu, L., Ding, W., Wu, F. and Li, J. (2016) Etching Synthesis of Iron Oxide Nanoparticles for Adsorption of Arsenic from Water. RSC Advances, 6, 15900-15910. https://doi.org/10.1039/C5RA26143K

[6] Chowdhury, M.N.K, Beg, M.D.H., Khan, M.R. and Mina, M.F. (2013) Synthesis of Copper Nanoparticles and Their Antimicrobial Performances in Natural Fibres. Materials Letters, 98, 26-29. https://doi.org/10.1016/j.matlet.2013.02.024

[7] Ghorbani, H.R. (2014) Chemical Synthesis of Copper Nanoparticles. Oriental Journal of Chemistry, 30, 15-18. https://doi.org/10.13005/ojc/300254

[8] Ghorbani, H.R. (2014) A Review of Methods for Synthesis of Al Nanoparticles. Oriental Journal of Chemistry, 30, 1941-1949. https://doi.org/10.13005/ojc/300456

[9] Ghorbani, H.R., Parsa Mehr, F., Pazoki, H. and Mosavar Rahmani, B. (2015) Synthesis of $\mathrm{ZnO}$ Nanoparticles by Precipitation Method. Oriental Journal of Chemistry, 31, 1219-1221. https://doi.org/10.13005/ojc/310281

[10] Hasany, S.F., Ahmad, I., Ranjan, J. and Rehman, A. (2012) Systematic Review of the Preparation Techniques of Iron Oxide Magnetic Nanoparticles. Nanoscience \& Nanotechnology, 2, 148-158. https://doi.org/10.5923/j.nn.20120206.01

[11] Hasnidawani, J.N., Azlina, H.N., Norita, H., Bonnia, N.N., Ratim, S. and Ali, E.S. (2016) Synthesis of ZnO Nanostructures Using Sol-Gel Method. Procedia Chemistry, 19, 211-216. https://doi.org/10.1016/j.proche.2016.03.095

[12] Iravani, S., Korbekandi, H., Mirmohammadi, S.V. and Zolfaghari, B. (2014) Synthesis of Silver Nanoparticles: Chemical, Physical and Biological Methods. Research in Pharmaceutical Sciences, 9, 385-406.

[13] Kumar, N. and Kumbhat, S. (2016) Essentials in Nanoscience and Nanotechnology. John Wily \& Sons, Inc., 31-74.

[14] Mohanty, U.S. (2011) Electrodeposition: A Versatile and Inexpensive Tool for the Synthesis of Nanoparticles, Nanorods, Nanowires, and Nanoclusters of Metals. Journal of Applied Electrochemistry, 41, 257-270. https://doi.org/10.1007/s10800-010-0234-3

[15] Munnings, C., Badwal, S.P.S. and Fini, D. (2014) Spontaneous Stress-Induced Oxidation of Ce Ions in Gd-Doped Ceria at Room Temperature. Ionics, 20, 1117-1126. https://doi.org/10.1007/s11581-014-1079-2

[16] Nabil, M. and Motawah, H.A. (2015) Silica Nanoparticle Preparation Using Alkaline Etching Process. Applied Mechanics and Materials, 749, 155-158. https://doi.org/10.4028/www.scientific.net/AMM.749.155 
[17] Pacioni, N.L., Borsarelli, C.D., Rey, V. and Veglia, A.V. (2015) Synthetic Routes for the Preparation of Silver Nanoparticles. In: Alarcon, E.I., Griffith, M. and Udekwu, K.I., Eds., Silver Nanoparticle Applications, Springer, Berlin, 13-46.

[18] Nie, M., Sun, K. and Meng, D.D. (2009) Formation of Metal Nanoparticles by Short-Distance Sputter Deposition in a Reactive ion Etching Chamber. Journal of Applied Physics, 106, Article ID: 05431. https://doi.org/10.1063/1.3211326

[19] Paskevicius, M., Webbb, J., Pitt, M.P., Blach, T.P., Hauback, B.C., Gray, E., Mac, A. and Buckley, C.E. (2009) Mechanochemical Synthesis of Aluminium Nanoparticles and Their Deuterium Sorption Properties to 2 Kbar. Journal of Alloys and Compounds, 481, 595-599. https://doi.org/10.1016/j.jallcom.2009.03.031

[20] Perekrestov, R., Kudrna, P. and Tichý, M. (2013) Deposition of $\mathrm{TiO}_{2}$ Nanoparticles by Means of Hollow Cathode Plasma Jet. Proceedings of Contributed Papers, Part II, 139-143.

[21] Prashant, K., Panchakarla, L.S. and Rao, C.N.R. (2011) Laser-Induced Unzipping of Carbon Nanotubes to Yield Graphene Nanoribbons. Nanoscale, 3, 2127-2129. https://doi.org/10.1039/c1nr10137d

[22] Ramesh, S. (2013) Sol-Gel Synthesis and Characterization of $\mathrm{Ag}_{3(2+x)} \mathrm{Al}_{x} \mathrm{Ti}_{4-x} \mathrm{O}_{11+} \delta$ $(0.0 \leq x \leq 1.0)$ Nanoparticles. Journal of Nanoscience, 2013, Article ID: 929321. https://doi.org/10.1155/2013/929321

[23] Rajput, N. (2015) Methods of Preparation of Nanoparticles-A Review. International Journal of Advances in Engineering \& Technology, 7, 1806-1811.

[24] Russo, P., Hu, A., Compagnini, G., Duley, W.W. and Zhou, N.Y. (2014) Femtosecond Laser Ablation of Highly Oriented Pyrolytic Graphite: A Green Route for Large-Scale Production of Porous Graphene and Graphene Quantum Dots. Nanoscale, 6, 2381-2389. https://doi.org/10.1039/C3NR05572H

[25] Semaltianos, N., Logothetidis, S., Perrie, W., Romani, S., Potter, R., Sharp, M., French, P., Dearden, G. and Watkins, K. (2008) CdSe Nanoparticles Synthesized by Laser Ablation. Europhysics Letters, 84, Article ID: 47001. https://doi.org/10.1209/0295-5075/84/47001

[26] Theivasanthi, T., Kartheeswari, N. and Alagar, M. (2013) Chemical Precipitation Synthesis of Ferric Chloride Doped Zinc Sulphide Nanoparticles and Their Characterization Studies. Chemical Science Transactions, 2, 497-507. https://doi.org/10.7598/cst2013.207

[27] Wang, L.S. and Hong, R.Y. (2011) Synthesis, Surface Modification and Characterization of Nanoparticles, Advances in Nanocomposites-Synthesis, Characterization and Industrial Applications. In Tech, London. http://www.intechopen.com

[28] Gordon, W.O., Morris, J.R. and Tissue, B.M. (2009) Control of Morphology in Inert-Gas Condensation of Metal Oxide Nanoparticles. Journal of Materials Science, 44, 4286-4295. https://doi.org/10.1007/s10853-009-3636-Z

[29] Wesolowski, M.J., Kuzmin, S., Wales, B., Sanderson, J.H. and Duley, W.W. (2013) Self-Assembly of Thin Carbon Micro-Shells through Pulsed Laser Irradiation of a Ferrocene/Benzene Solution. Journal of Materials Science, 48, 6212-6217. https://doi.org/10.1007/s10853-013-7418-2

[30] Yadav, T.P., Yadav, R.M. and Singh, D.P. (2012) Mechanical Milling: A Top down Approach for the Synthesis of Nanomaterials and Nanocomposites. Nanoscience and Nanotechnology, 2, 22-48. https://doi.org/10.5923/j.nn.20120203.01

[31] Arul Dhas, N., Paul Raj, C. and Gedanken, A. (1998) Synthesis, Characterization, and Properties of Metallic Copper Nanoparticles. Chemistry of Materials, 10, 1446-1452. https://doi.org/10.1021/cm9708269 
[32] Huang, H.H., Yan, F.Q., Kek, Y.M., et al. (1997) Synthesis, Characterization, and Nonlinear Optical Properties of Copper Nanoparticles. Langmuir, 13, 172-175. https://doi.org/10.1021/la9605495

[33] Baco-Carles, V., Datas, L. and Tailhades, P. (2011) Copper Nanoparticles Prepared from Oxalic Precursors. International Scholarly Research Network, 2011, Article ID: 729594. https://doi.org/10.5402/2011/729594

[34] Kapoor, S. and Mukherjee, T. (2003) Photochemical Formation of Copper Nanoparticles in Poly(N-vinylpyrrolidone). Chemical Physics Letters, 370, 83-87. https://doi.org/10.1016/S0009-2614(03)00073-3

[35] Khodashenas, B. and Ghorbani, H.R. (2014) Synthesis of Copper Nanoparticles: An Overview of the Various Methods. Korean Journal of Chemical Engineering, 31, 1105-1109. https://doi.org/10.1007/s11814-014-0127-y

[36] Kruk, T., Szczepanowicz, K., Stefańska, J., Socha, R.P. and Warszyński, P. (2015) Synthesis and Antimicrobial Activity of Monodisperse Copper Nanoparticles. Colloids and Surfaces B: Biointerfaces, 128, 17-22. https://doi.org/10.1016/j.colsurfb.2015.02.009

[37] Nasrollahzadeh, M. and Sajadi, M. (2015) Green Synthesis of Copper Nanoparticles Using Ginkgo biloba L. Leaf Extract and Their Catalytic Activity for the Huisgen [3+2] Cycloaddition of Azides and Alkynes at Room Temperature. Journal of Colloid and Interface Science, 457, 141-147. https://doi.org/10.1016/j.jcis.2015.07.004

[38] Park, B.K., Jeong, S., Moon, J., Lim, S. and Kim, J.S. (2007) Synthesis and Size Control of Monodisperse Copper Nanoparticles by Polyol Method. Journal of Colloid and Interface Science, 311, 417-424. https://doi.org/10.1016/j.jcis.2007.03.039

[39] Raja, M., Shuba, J., Ali, F.B. and Ryu, S.H. (2008) Synthesis of Copper Nanoparticles by Electroreduction Process. Materials and Manufacturing Processes, 23, 782-785. https://doi.org/10.1080/10426910802382080

[40] Ramyadevi, J., Jeyasubramanian, K., Marikani, A., Rajakumar, G. and Rahuman, A.A. (2012) Synthesis and Antimicrobial Activity of Copper Nanoparticles. Materials Letters, 71, 114-116. https://doi.org/10.1016/j.matlet.2011.12.055

[41] Song, X., Sun, S., Zhang, W. and Yin, Z. (2004) A Method for the Synthesis of Spherical Copper Nanoparticles in the Organic Phase. Journal of Colloid and Interface Science, 273, 463-469. https://doi.org/10.1016/j.jcis.2004.01.019

[42] Habib, M.H., Kamrani, R. and Mokhtari, R. (2012) Fabrication and Characterization of Copper Nanoparticles Using Thermal Reduction: The Effect of Nonionic Surfactants on Size and Yield of Nanoparticles. Microchimica Acta, 171, 91-95.

[43] Salavati-Niasari, M. and Davar, F. (2009) Synthesis of Copper and Copper (I) Oxide Nanoparticles by Thermal Decomposition of a New Precursor. Materials Letters, 63, 441-443. https://doi.org/10.1016/j.matlet.2008.11.023

[44] Salavati-Niasari, M., Fereshteh, Z. and Davar, F. (2009) Synthesis of Oleylamine Capped Copper Nanocrystals via Thermal Reduction of a New Precursor. Polyhedron, 28, 126-130. https://doi.org/10.1016/j.poly.2008.09.027

[45] Zhong, C.J., Kotov, N.A., Daniell, W. and Zamborini, F.P. (2006) Nanoparticles and Nanostructures in Sensors and Catalysis. Materials Research Society Symposium Proceedings, 900E, 0900-O09-10.1-10.6. 